\title{
Perineal Rectosigmoidal Resection for Complete Rectal Prolapse
}

\author{
Hussein Abduljabbar Shihab Al-Katrani* (D), Mamoon Othman Khalid Alabdulla \\ Department of Surgery, AL-Mawani Teaching Hospital, Basrah Health Directorate, Ministry of Health and Environment, \\ Basrah, Iraq
}

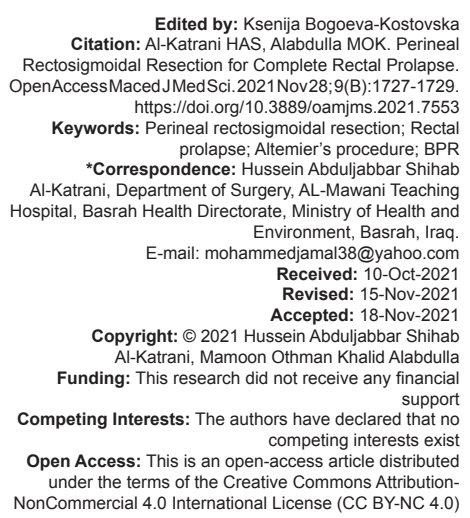

Edited by: Ksenija Bogoeva-Kostovska Edited by: Ksenija Bogoeva-Kostovska
Citation: Al-Katrani HAS, Alabdulla MOK. Perineal Rectosigmoidal Resection for Complete Rectal Prolapse. Rectosigmoidal Resection for Complete Rectal Prolapse
OpenAccess Maced JMedSci.2021 Nov28; 9 (B):1727-1729. https://doi.org/10.3889/oamjms.2021.7553
henAccess Maced Keywords: Perineal rectosigmoidal resection; Rectal prolapse; Altemier's procedure; BPR *Correspondence: Hussein Abduljabbar Shihab Al-Katrani, Department of Surgery, AL-Mawani Teaching Hospital, Basrah Health Directorate, Ministry of Health and Environment, Basrah, Iraq.
E-mail: mohammedjamal38@yahoo.com Received: 10-Oct-2021 Revised: $15-\mathrm{Nov}-2021$ Copyright: $\odot 2021$ Hussein Abduljabbar Shihab Al-Katrani, Mamoon Othman Khalid Alabdulla Funding: This research did not receive any financial Competing Interests: The authors have declared that no Open Access: This is an open-ang interests exis Open Access: This is an open-access article distributed NonCommercial 4.0 International License (CC BY-NC 4.0)

\begin{abstract}
BACKGROUND: Rectal prolapse (RP) (rectal Providencia) is a disorder manifest by full-thickness intussusceptions of the rectal wall that protrudes externally through the anus.

AIM: A retrospective study was done to evaluate the outcome of rectosigmoidal resection for complete recta prolapse (CRP) in our hospital from 2008 to 2020.

METHODS: This study analyzes the data of post-operative outcomes for 25 patients with CRP treated by perinea rectosigmoidal resection; eight patients were male and 17 were female.

RESULTS: A total of 25 patients enrolled with the median age of 50 years. There was an improvement in the genera condition of patients regarding constipation, bleeding per rectum, incontinence, and perineal discomfort. There were
\end{abstract} no mortality, no major complication, and a low recurrence rate.

CONCLUSION: Altemier's procedure for CRP improves patients' general condition regarding constipation and incontinence, no mortality, low complication rate, and negligible rate of recurrence.

\section{Introduction}

Rectal prolapse (RP) (rectal Providencia) is a disorder manifest by full-thickness intussusceptions of the rectal wall that protrudes externally through the anus [1]. It may be confined to the rectum (rectorectal intussusceptions), descends into the anal canal (rectoanal intussusceptions), or extends beyond the anal verge (external rectal prolepses) [2]. The incidence of RP has been determined about 2.5/100.000 population [3]. It occurs at extremes of age with clear predominance in elderly women [4]. Although it is a benign condition, it can be debilitating because of the discomfort both internally and externally, associated with drainage of mucus and blood due to ulcer or abrasion of wall mucosa [5]. Approximately 50-75\% of patients with RP have fecal incontinence and $25-50 \%$ of patients have constipation [6]. It is called obstruction defecation syndrome when associated with a mixed pattern of functional disorder ranging from the difficulty of the evacuation of stool to fecal incontinence [7]. Incontinence in RP may be explained by disturbs of the sphincter mechanism, a chronic stretch of sphincter by prolapse itself [8]. Up to half of the patients with prolapse demonstrate pudendal nerve neuropathy which may be responsible for atrophy of the external sphincter mechanism [9]. Constipation results from intussuscepting bowel in the rectum creating a blockage that is exacerbated by straining and pelvic floor dyssynergia [10].

\section{Materials and Methods}

All patients were admitted to the surgical ward, full history and physical examination were done including age, type, and number of delivery in female. History of the previous pelvic and anal operation, pelvic trauma, chronic illness, history of bowel function (frequency, constipation, incontinence, and bleeding per rectum), family history of RP, body mass index, and American society of anesthesia score (ASA) for each patients. Proctological examination, abdominal ultrasound, and pelvic magnetic resonance imaging were done.

Pre-operative mechanical and chemical bowel preparation with laxative and systemic antibiotics, thrombotic prophylaxis was given to the patients before surgery. Under general anesthesia and lithotomy position, Foleys catheter introduced, rectomigmoidectomy was performed using Altemier's 
procedure including circumferential incision of $2 \mathrm{~cm}$ above the dentate line to avoid injury to the anal sphincter, pulling the redundant rectum and colon by more dissection of mesorectum and mesocolon close to the rectal wall to avoid nerve injury, resection of redundant rectum and end to end anastomoses by hand-sewn technique was done. Levatorplasty (anterior and posterior) was done for thin levatore ani. The median duration of procedure was 60 (50-125) minutes and the median length of the resected segment of bowel was (10-25) cm, the mean length of hospital stay was 2 (1-4) days, follow-up of patients after 1 week, 2 weeks, 1 month, and 6 months asking about post-operative complication and disappearance of preoperative symptoms (incontinence, discomfort, urinary symptoms, sexual function, and recurrence).

\section{Results}

From 2010 to 2020, 25 patients with CRP underwent Altimeter's operation. The median age was 55 (40-65) years, and M: F ratio was 1:2 (eight males and 17 females). All patients were of ASA score (II and III) (Table 1), comorbid illness DM, HT, and bronchial asthma. The median duration of prolapse before surgery was 12 (6-60) months, and there were no patients who had previous surgery for RP, the operation time was 100 (90-160) min, the coloanal anastomoses were done manually (handsewn) technique and no stapler was used, levator anoplasty was done in all patients. There were no post-operative death and no major complications such as anastomoses leak, sepsis, pulmonary embolism, or bleeding (Table 2). There was no recurrence, and there was an improvement of pre-operative symptoms regarding constipation, bleeding, and incontinence.

Table 1: Patients characteristics

\begin{tabular}{ll}
\hline Patients No. & No. (\%) \\
\hline Gender (M/F) & $8 / 17$ \\
Median age (years) & 50 \\
Anesthetics risk (\%) American society of anesthesiologist & \\
ASA I & $13(52)$ \\
ASA II & $7(28)$ \\
ASA III & $5(20)$ \\
ASA IV & 0 \\
Duration of prolapse (months) & $12(6-16)$ \\
\hline ASA: American society of anesthesia score. &
\end{tabular}

The median follow-up time was 12 (1-60) months. There was no sexual dysfunction in sexually active patients. Post-operative analgesia was needed in the form of tramadol or pethidine $100 \mathrm{mg}$. The median

Table 2: Morbidity and mortality after rectosigmoid resection in the literature [16]

\begin{tabular}{llll}
\hline Study & No. of patient & Morbidity & Mortality \\
\hline Elagili (2015) & 22 & 22 & 0 \\
Mario (2019) & 43 & $2.30 \%$ & 0 \\
Kimmins (2001) & 63 & $10 \%$ & 0 \\
Cirocco (2010) & 103 & $14 \%$ & 0 \\
Lee (2010) & 143 & $13.80 \%$ & 0 \\
Ris (2011) & 60 & $35 \%$ & $1.60 \%$ \\
Our series & 25 & 0 & 0 \\
\hline
\end{tabular}

hospital stays were 3 (2-3) days, with no recurrence of prolapses in our patients.

\section{Discussion}

Rectosigmoid resection for CRP is a safe operation, minimally invasive procedure that leaves no scar or post-operative adhesion. We do not use protective ileostomy. As compared with abdominal approaches which are associated with post-operative adhesion of pelvic organs which may lead to infertility in young females and erectile dysfunction in males due to pelvic nerve injury, also abdominal resection may be associated with the anastomotic leak. There is less post-operative pain as compared with the abdominal approach with a negligible major complication and no post-operative mortality. There are no recurrence and less hospital stay which are explained by the selection of our patients without a history of risk factors such as obesity, previous pelvic surgery, recurrent prolapse, high ASA score, and extremities of age (Table 3 ). There is no affection of the pelvic nerve in a sexually active person. Frequency and urgency may increase due to reduce capacity and wall compliance of the rectum. Levatorplasty improves continence in the majority of patients. Altemier's procedure is regarded as a safe procedure for elderly patients with comorbid illness and spinal anesthesia can be used for unfit patients to avoid the stress and risk of general anesthesia with rapid recovery and early bowel movement and function.

Table 3: Results following rectosigmoid resection. literature review [17]

\begin{tabular}{lllllll}
\hline Author & Year & $\begin{array}{l}\text { No. } \\
\text { Patients }\end{array}$ & $\begin{array}{l}\text { Mean } \\
\text { of age }\end{array}$ & $\begin{array}{l}\text { Follow } \\
\text { up (M) }\end{array}$ & \% Recurrence & \% Improvement \\
\hline Altemier et al. & 1971 & 106 & 64 & - & 3 & - \\
Zbar et al. & 2002 & 80 & 69 & 22 & 3.8 & 100 \\
Habr-Gama & 2006 & 44 & 76 & 49 & 7.1 & 85.7 \\
Boccasanta & 2006 & 40 & 71 & 28 & 12.5 & 100 \\
Chun et al. & 2004 & 109 & 76 & 29 & 16.5 & 100 \\
Prasad et al. & 1986 & 25 & 71 & 36 & 0 & 88 \\
Johansen & 1993 & 20 & 82 & 26 & 0 & 25 \\
et al. & & & & & & 78 \\
Vasikevsky & 1987 & 66 & - & 31 & 0 & 100 \\
Our study & 2021 & 25 & 59 & 24 & 0 & \\
\hline
\end{tabular}

The majority of the affected patients are elderly females due to the sequela effect of pregnancy and menopause on the pelvic floor [11]. The condition found in men due to loss of sacral fixation of the rectum and underlying connective tissue disorder that increased intra-abdominal pressure secondary to (obesity, chronic cough, and weight lifting), chronic dysmotility, chronic straining, and perineal hypermotility [12]. More recently, it has been suggested that morphological changes in enteric ganglia may cause RP [13]. Surgical management of CRP can be classified into abdominal, perineal, and laparoscopic. The abdominal approaches include suture rectopexy (suture fixation of rectosigmoid to the presacral fascia), resection rectopexy (involving sigmoid colectomy with rectopexy), and mesh rectopexy 
(placement of mesh below the sacral promontory at the presacral fascia posteriorly anchoring the rectum). These procedures are associated with an increased risk of sexual dysfunction and presacral bleeding. Perineal approaches include perineal rectosigmoidectomy (Altemiers), mucosal sleeve resection (Delorme), and perineal stapled prolapse resection [14]. These operations for high-risk patients can be done under regional or local anesthesia and they are slightly less effective in controlling prolapse as compare with abdominal approaches. Laparoscopic ventral mesh rectopexy achieved excellent results regarding low recurrence and complication rates and improvement in bowel function but it is not universally employed [15]. The aim of this study was to assess the outcome of perineal rectosigmoid resection (Altemiers) in the treatment of CRP regarding recurrence, complication rate, and functional outcome.

\section{Conclusion}

Altemier's procedure for CRP improves patients' general condition regarding constipation and incontinence, no mortality, low complication rate, and negligible rate of recurrence.

\section{References}

1. Collinson R, Cunningham C, Costa HD, Lindsey I. Rectal intussusception and unexplained fecal incontinence: Findings of a proctographic study. Colorectal Dis. 2009:11(1):7783. https:// doi.org/10.1111/j.1463-1318.2008.01539.x PMid:18462221

2. Dvorkin L, Knowles CH, Scott SM, Williams NS, Lunniss PJ. Rectal intussusception: Characterization of symptomatology. Dis Colon Rectum. 2005;48(4):824. https://doi.org/10.1007/ s10350-004-0834-2 PMid:15785903

3. Kairaluoma MV, Kellokumpu IH. Epidemiologic aspects of complete rectal prolapse. Scand J Surg. 2005;94(3):207-10. https://doi.org/10.1177/145749690509400306 PMid:16259169

4. Gallo JG, Pellino GM. Consensus statement of the Italian society of colorectal surgery (SICCR): Management and treatment of complete rectal prolapse. Techn Colpoproctol. 2018;22(12):919-31. https://doi.org/10.1007/ s10151-018-1908-9

PMid:30554284

5. Bordeianou L, Hicks CW, Kaiser AM, Alavi K, Sudan R, Wise PE.
Rectal prolapse: An overview of clinical features, diagnoses, and patient-specific management strategies. J Gastrointest Surg. 2014,18:10591069. https://doi.org/10.1007/s11605-013-2427-7 PMid:24352613

6. Senagore AJ. Management of rectal prolapse: The role of laparoscopic approaches. Semin Laproscopic Surg. 2003,10:197202. https://doi.org/10.1177/107155170301000407 PMid: 14760468

7. Trompetto M, Tutino R. Altemeiers procedure for complete rectal prolapse, outcome, and function in 43 consecutive female patients. BMC Surg. 2019;19:10. https://doi.org/10.1186/ s12893-018-0463-7

8. Hawkins AT, Olariu AG, Savitt LR, Gingipally S, Wakamatsu MM, Pulliam S, et al. Impact of rising grades of internal rectal intussusception on fecal continence and symptoms of constipation. Dis Colon Rectum. 2016;59(1):5461. https://doi. org/10.1097/DCR.0000000000000510

PMid:26651113

9. Glascow SC, Birnbaun EH, Kodner IJ, Fleshman JW, Dietz DW Preoperative anal manometry predicts continence after perineal proctectomy for rectal prolapse. Dis Colon Rectum. 2006;49:10521058. https://doi.org/10.1007/s10350-006-0538-x PMid: 16649117

10. Schultz I, Mellgren A, Dolk A, Johansson C, Holmstrom B. Longterm results and functional outcome after Ripstein rectopexy. Dis Colon Rectum. 2000;43:3543. https://doi.org/10.1007/ BF02237241

PMid:10813121

11. Rodrigo N, Shek KL, Dietz HP. Rectal intussusception is associated with abnormal levator ani muscle structure and morphology. Tech Coloproctol. 2011;15(1):39-43. https://doi. org/10.1007/s10151-010-0657-1 PMid:21086012

12. Hotouras A, Murphy J. Symptom distribution and anorectal physiology result in male patients with rectal intussusception and prolapse. JSR 2014;188(1):198-302. https://doi.org/10.1016/j. jss.2013.12.008

PMid:24411299

13. Zorenkov D, Otto S, Bottner M, Morphological alteration of the enteric nervous system in young male patients with rectal prolapse. Int J Colorectal Dis 2011;26(11):1483. https://doi. org/10.1007/s00384-011-1282-9

PMid:21800050

14. Saleh Eftaiha S, Nordenstam J, Rectopexy V. The new option for rectal procidentia. In: Seminars in the Colon and Rectal Surgery. Netherlands: Elsevier; 2021. http://doi.org/10.1053/j. scrs.2015.12,011

15. Emile $\mathrm{SH}$, Elfeki $\mathrm{H}$. Perineal resection procedure for the treatment of complete rectal prolapse: A systematic review of the literature. Int J Surg. 2017;46:146-54. http://doi.org/10.1016/j. ijsu-2017.09.005

PMid:28890414

16. Trompetto M. Altemiers procedure for complete rectal prolapse; outcome and function in 43 consecutive female patients. BMC Surg. 2019;19:10.

17. Altomare DF. Long-term outcome of Altemiers procedure for rectal prolapse. Dis Colon Rectum 2009;52(4):698-703. http:// doi.org/10.1007/DCR.0b013e31819ecffe

PMid:19404077 